Provided for non-commercial research and education use. Not for reproduction, distribution or commercial use.

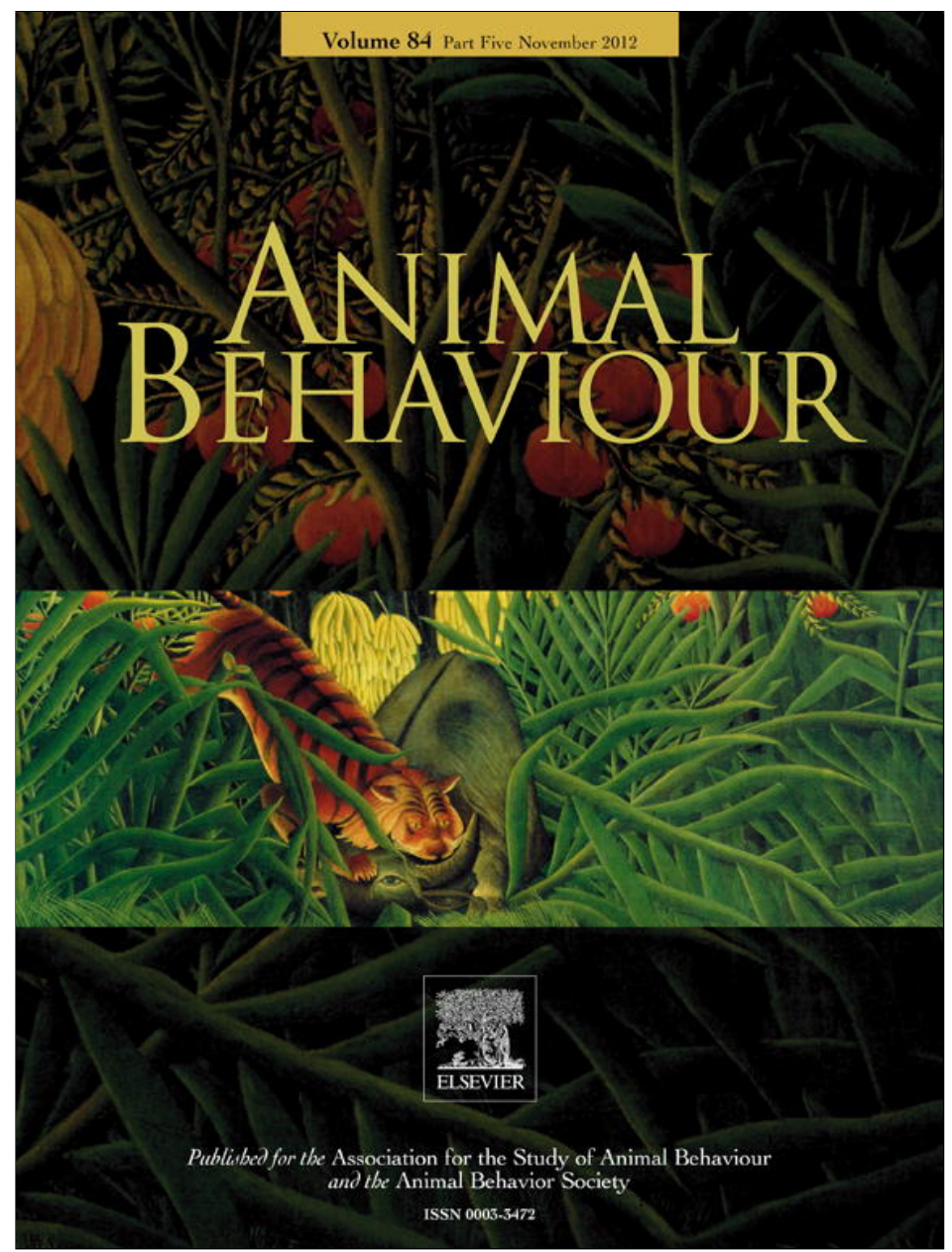

This article appeared in a journal published by Elsevier. The attached copy is furnished to the author for internal non-commercial research and education use, including for instruction at the authors institution and sharing with colleagues.

Other uses, including reproduction and distribution, or selling or licensing copies, or posting to personal, institutional or third party websites are prohibited.

In most cases authors are permitted to post their version of the article (e.g. in Word or Tex form) to their personal website or institutional repository. Authors requiring further information regarding Elsevier's archiving and manuscript policies are encouraged to visit:

http://www.elsevier.com/copyright 


\title{
Dominant nestlings displaying female-like melanin coloration behave altruistically in the barn owl
}

\author{
Alexandre Roulin $^{\mathrm{a}, *}$, Arnaud Da Silva ${ }^{\mathrm{b}}$, Charlène A. Ruppli ${ }^{\mathrm{a}}$ \\ a Department of Ecology and Evolution, Biophore, University of Lausanne, Lausanne, Switzerland \\ ${ }^{\mathrm{b}}$ Biogeosciences, University of Burgundy, Dijon, France
}

\section{A R R T I C L E I I N F O}

\section{Article history:}

Received 8 May 2012

Initial acceptance 18 June 2012
Final acceptance 21 August 2012

Available online 23 September 2012

MS. number: 12-00348R

\section{Keywords:}

altruism

barn owl

cooperation

egoism

food sharing

food stealing

melanin

selfish

sibling competition

Tyto alba
When competing over parental resources, young animals may be typically selfish to the point of siblicide. This suggests that limited parental resources promote the evolution of sibling competition rather than altruistic or cooperative behaviours. In striking contrast, we show here that in $71 \%$ of experimental threechick broods, nestling barn owls, Tyto alba, gave food to their siblings on average twice per night. This behaviour prevailed in the first-born dominant nestlings rather than the last-born subordinate nestlings. It was also more prevalent in individuals displaying a heritable dark phaeomelanin-based coloration, a typical female-specific plumage trait (owls vary from dark reddish to white, females being on average darker reddish than males). Stealing food items from siblings, which occurred in $81 \%$ of the nests, was more frequent in light than dark phaeomelanic dominant nestlings. We suggest that food sharing has evolved in the barn owl because parents store prey items in their nest that can be used by the offspring to feed their nestmates to derive indirect (kin selection) or direct benefits (pseudoreciprocity or by-product mutualism). The cost of feeding siblings may be relatively low for dominant individuals while the indirect genetic benefits could be high given that extrapair paternity is infrequent in this species. Thus, in situations in which young animals have access to more food resources than they currently need, they can altruistically share them with their siblings.

(c) 2012 The Association for the Study of Animal Behaviour. Published by Elsevier Ltd. All rights reserved.
The evolution of helping where an individual increases the direct fitness of another individual is a fascinating topic. Two categories of evolutionary pathways can account for the emergence of helping behaviour. When individuals gain direct material benefits from helping they are said to behave cooperatively and when they derive indirect genetic benefits the helping behaviour is referred to as altruistic (Lehmann \& Keller 2006; Bshary \& Bergmüller 2007). The typical situation in which individuals derive indirect fitness benefits is when the genetic benefits of helping related individuals outweigh the cost of helping (Hamilton 1964; Hatchwell 2010). An individual may also help a conspecific (related or not) in the hope that it will reciprocate on another occasion (Trivers 1971); even if reciprocation does not occur the helper may still derive material benefits if increasing the survival of surrounding individuals is beneficial (pseudoreciprocity or byproduct mutualism hypotheses, Leimar \& Hammerstein 2010). For instance, helping may increase group size, which can decrease the

\footnotetext{
* Correspondence: A. Roulin, Department of Ecology and Evolution, University of Lausanne, 1015 Lausanne, Switzerland.

E-mail address: Alexandre.Roulin@unil.ch (A. Roulin).
}

risk of predation (Kokko et al. 2001) or induce parents to provide more food resources at the nest (Kilner et al. 2004). Helping behaviour among family members has been studied in depth in the context of so-called cooperative breeding where mature offspring help raise their parents' new offspring (Clutton-Brock 2002; Bergmüller et al. 2007). In contrast, interactions between siblings still dependent on their parents are considered as conflictual rather than harmonious (Trivers 1974).

Conflicts between siblings take their root in the mismatch between parental food supply and offspring food demand leading to intense sibling competition to monopolize the limited resources. Parents do not provide all the food requested by their offspring because reproductive activities are costly, they face a trade-off between offspring number and quality, and they often produce more offspring than they can rear to independence (Mock \& Parker 1997). The evolutionary outcome of limited parental resources is therefore predicted to be sibling rivalry rather than sibling cooperation or altruism. This led biologists interested in the evolutionary implications of parental care to consider Hamilton's rule useful not only to specify the conditions promoting altruism but also the conditions that promote selfish behaviour. This so-called 'inverse Hamilton's rule' states that an allele coding for 
selfishness will spread if the benefits of being selfish exceed the costs to the victim multiplied by the coefficient of relatedness between the selfish individual and the victim (Mock \& Parker 1997).

In line with the view that interactions between siblings are conflictual rather than harmonious, altricial offspring have only been anecdotally reported to help their siblings obtain parental resources (Marti 1989). Frequent observations of aggressive competition between siblings over parental attention to the point of siblicide suggest that conflicts of interests between young siblings indeed promote the evolution of selfish rather than altruistic or cooperative behaviours (Mock \& Parker 1997). Sibling rivalry over parental resources may hamper the evolution of helping relatives if the indirect genetic benefits gained from helping kin are inferior to their costs (West et al. 2002). For instance, dominant offspring may behave more selfishly with their siblings to impose their physical superiority (Drummond et al. 2003). Since altruistic or cooperative interactions between young siblings that are still dependent on their parents appear to be infrequent (with the exception of humans; Kramer 2011), little is known about the factors that could induce helping behaviours among them. As sharing the same family unit is an individual's first social experience, family interactions may have facilitated the evolutionary transition from selfishness to helping, while helping behaviours may reinforce family bonds (von Bayern et al. 2007).

Sharing parental food resources with siblings may occur in species in which parents store food in their nest. If some individuals have privileged access to stored resources and are unable to utilize all of them, they may be selected to share them with hungry siblings that have less access to these resources. Such helping behaviour can evolve if individuals that help their siblings obtain parental resources derive direct or indirect fitness benefits (Lehmann \& Keller 2006; Bshary \& Bergmüller 2007; West et al. 2007). Reciprocity would be the most likely type of direct benefits. An individual may share food with a sibling in expectation of a future return from it that will compensate for the costs of the initial cooperative investment (e.g. Wilkinson 1992). In other words, a helper individual shares surplus parental resources with their hungry siblings in the hope that they will reciprocate once the helper is hungry. Another category of direct benefits, so-called pseudoreciprocity or by-product mutualism, is if, by feeding siblings, helper offspring release their parents from spending time distributing food among the progeny, which would allow them to invest more time in foraging and increase the total amount of food brought to the progeny. Alternatively, helping siblings may enhance their survival and thereby reduce the helper's risk of being killed by a predator or increase the total begging solicitation levels produced by progeny to stimulate parents to come back rapidly with food. Indirect genetic benefits may occur through kin selection, if the costs entailed by food sharing are compensated for by the increased survival of related individuals.

Species such as raptors, in which food is often stored in the nest (e.g. Korpimäki 1987; Bakaloudis et al. 2012), are prime candidates to examine the evolution of helping behaviour between young siblings that are still dependent on their parents. We performed a study in the barn owl, Tyto alba, in which sharing food between siblings has been observed in both Europe (Epple 1979; Bühler 1981; Kniprath \& Stier-Kniprath 2010) and North America (Marti 1989). Parents usually bring prey items more rapidly than their offspring can consume them (Baudvin 1980; Roulin 2001, 2004a). If food-satiated nestlings do not relinquish the accumulated prey remains, they can defend access to the prey for later consumption, for instance, by sitting on them to reduce the risk of being robbed, which is relatively frequent in barn owls (Roulin et al. 2008a). Alternatively, nestlings may feed their siblings if the latter did not notice the presence of surplus prey remains in their dark nest. The barn owl is particularly interesting also because pronounced hatching asynchrony gives an edge to the first-born individuals, which have easier access to parental food resources than later-born siblings. The $2-10$ eggs hatch on average every $2-3$ days, which generates a pronounced age and size hierarchy between siblings. The first-born dominant individuals may face a choice between monopolizing stored food for later consumption or feeding their subordinate siblings. Furthermore, barn owl plumage varies strongly from dark reddish (phaeomelanic) to white (nonphaeomelanic) and from immaculate (noneumelanic) to heavily marked with large black spots (eumelanic), traits for which the expression is under strong genetic control and not, or weakly, sensitive to environmental factors (Roulin \& Dijkstra 2003). Appetite is higher in lightly eumelanic and darker phaeomelanic individuals (Dreiss et al. 2010a), and darker phaeomelanic individuals increase their body mass more rapidly than lighter coloured ones when food is available in large quantities (Roulin et al. 2008b). Plumage traits might thus advertise the propensity to share food with siblings.

We examined whether barn owl nestlings are more likely to derive direct or indirect fitness benefits by sharing food with siblings. Under the reciprocity hypothesis, helpers share food with their siblings in the hope that they will reciprocate at a later time. If this is the case, we predicted that an individual that received a food item from a sibling would feed it on another occasion. Alternatively, dominant nestlings may feed their younger siblings to release their parents from taking care of offspring that still need assistance in the nest, thereby inducing their parents to spend more time foraging. In this case, we expected parental feeding rate to be higher in broods in which food sharing occurred. Because higher parental feeding rates will be more beneficial to hungry than satiated individuals, we also predicted food sharing would prevail mainly in nests in which nestlings were in poorer condition. Under the kin selection hypothesis (but also the pseudoreciprocity and by-product mutualism hypotheses), we expected that food sharing would be expressed by individuals for which the costs of being generous were low while the potential benefits were high. Thus, in contrast to the reciprocity hypothesis, only nestlings with privileged access to food resources would share them with the siblings that were so needy that they were unlikely to reciprocate at a later time. In the barn owl, since the first-born nestlings (so-called seniors) are better able to obtain food than their younger siblings (i.e. juniors; Roulin 2004b), sharing food with siblings should be less costly for seniors while the benefit of being fed by nestmates should be greater for juniors. Therefore, if nestling barn owls share food with siblings because they derive indirect genetic benefits (or direct benefits as predicted by the pseudoreciprocity and by-product mutualism hypotheses), we predicted that seniors would feed their junior siblings more frequently than the opposite.

To test these predictions, we recorded interactions between nestlings in the field in experimentally reduced broods of three individuals: a senior, a junior and a middle-born sibling. Observations were carried out for one night from 1900 to 0700 hours the following morning. Since short-term experimental brood reduction does not alter parental feeding rate (Roulin et al. 2000), our design ensured that food was available in large enough quantities to induce food sharing. Therefore, intrinsically altruistic individuals were expected to have the opportunity to feed siblings with prey items that accumulated in the nest. Since barn owl nestlings frequently steal food from each other (Roulin et al. 2008a), we also investigated whether the degree of generosity (i.e. food sharing) was inversely related to the degree of selfishness (i.e. food stealing). 


\section{METHODS}

The study was carried out in 2007 in western Switzerland on a wild population of barn owls breeding in nestboxes located on barn walls. The age of each nestling was determined soon after hatching by frequent nest visits during this period. We recognized each chick by clipping different combinations of toenails before ringing them with one or two aluminium numbered rings. Each individual was thus easily recognizable on the video footage because one individual was ringed on the left leg, another on the right leg and the third on both legs. Also, size differences between siblings are so pronounced that we could verify that our data scoring was reliable. At 1900 hours we reduced brood sizes (mean $\pm \mathrm{SE}=5.8 \pm 0.2$ ) to three individuals by removing all nestlings except the first (mean $\pm \mathrm{SE}=42 \pm 1$ days of age), middle $(38 \pm 2)$ and last-born individuals $(34 \pm 2)$; the mean age difference between junior and senior nestmates was $9 \pm 1$ days. During recording nights from 1900 to 0700 hours, we placed the extra nestmates in a ventilated box located at some distance from the nest. One day before the experiment, we installed an infraredsensitive camera in the nestboxes, and we recorded the three siblings from 1900 to 0700 hours the next morning. We never observed any sign of distress in adults and nestlings.

We scored phaeomelanin-based coloration when nestlings were 50 days of age by comparing their colour with eight chips ranging from 1 for dark reddish to 8 for white, a highly repeatable method (Roulin 1999). We measured the size of black spots with a calliper to the nearest $\mathrm{mm}$, also a reliable method (Roulin 1999). We could measure plumage traits in 38 of the 43 nestlings, explaining disparities in sample size between analyses. Sex of nestlings was determined using molecular markers (Py et al. 2006). A body condition index was given by the residuals of the regression of body mass on wing length $\left(F_{1,52}=18.63, P<0.0001\right)$.

When the offspring are more than 3 weeks of age, parents typically feed them by transferring food items from bill to bill. Parents appear to give priority to the offspring that begs at a high level (Dreiss et al. 2010b), and before resuming hunting activities the mother and father stay in the nest alongside their offspring for on average 29 and 15 s, respectively (Roulin \& Bersier 2007). During this period the mother is frequently looking for stored prey items in order to transfer them to the offspring that continues to beg loudly (A. Roulin, A. Da Silva \& C. Ruppli, personal observations).

Food sharing between siblings was defined as the transfer of a prey item from bill to bill, either actively (with the donor going towards the recipient to give its item) or passively (it was unclear whether the donor was giving the item or whether the recipient took it). Passive transfer of food was considered to be food sharing because the donor showed hardly any sign of avoiding the transfer. Food stealing was defined as any successful or unsuccessful attempt to take a food item (with the bill) from a sibling that was consuming it. Food-stealing events are easy to identify because the two siblings drag the prey in opposite directions.

\section{Statistical Procedure}

Before reporting the tests of predictions, we first describe parental feeding behaviour and nestling food consumption in order to have a better picture of family interactions taking place when nestlings handle prey items. First, to investigate whether seniors, middle-born nestlings and juniors had equal opportunities to redistribute food to their siblings, we examined differences in the number of prey items each individual received from the parents, how many items they consumed, how many items they did not entirely consume and how fast they ate. We analysed all variables using linear mixed models (LMM) when the data were normally distributed and if this was not the case we performed generalized linear mixed models (GLMM) with Poisson error distribution. To investigate the effect of the within-brood age hierarchy (i.e. senior, middle-born, junior), we fitted age rank as an independent variable. We also accounted for the effects of nestling sex, colour and 'absolute age' (in number of days) as covariates.

To test whether food sharing varied between and within broods according to variations in food supply, we examined whether food sharing was related to hunger level, that is, whether its occurrence varied during the night and was associated with the number of prey items available in the nest. To test whether nestlings differed in their propensity to share food with siblings according to age rank (seniors, middle-born nestlings and juniors), absolute age, sex and coloration, we used similar linear mixed models as described above. Similarly, we tested interbrood and interindividual variations in food stealing.

Because all statistical analyses including the size of black eumelanic spots were not significant, we present only analyses carried out on phaeomelanin-based reddish coloration. Also, the initial size of the brood out of which we created the experimental three-chick broods was not associated with the number of prey items that were shared between three isolated siblings (Spearman correlation: $r_{\mathrm{S}}=-0.13, N=21$ broods, $P=0.58$ ) or stolen from siblings $\left(r_{\mathrm{S}}=0.26, N=21\right.$ broods, $P=0.25$ ). For this reason, we do not consider brood size in subsequent analyses.

All (G)LMM included nest identity as random intercept because nestmates could not be considered as independent statistical units. We ran all statistical analyses using SAS v 9.2 (SAS Institute inc., Cary, NC, U.S.A.). We used the REML method for GLMM, and MIXED or GLIMMIX procedures for LMM. We performed backward model selection with final models only containing significant effects, and main effects involved in significant interactions. Residuals from linear mixed models were checked for normality. Statistical analyses are two tailed and $P$ values lower than 0.05 are considered significant. Means are quoted $\pm \mathrm{SE}$.

\section{Ethical Note}

This experiment was carried out under the legal authorization of the 'Service vétérinaire du Canton de Vaud' (1508.3). A similar procedure was used as previously explained in other papers (see ethical note in Roulin \& Bersier 2007). As in previous studies (Roulin et al. 2000; Dreiss et al. 2010b), we offered dead laboratory mice to nestlings that remained in the ventilated box from 1900 to 0700 hours. At 0700 hours we put them back in their nest. These individuals were old enough to consume two to three mice by themselves whenever they wanted. Our study was not detrimental to the birds because parents never abandoned broods and temporarily reducing brood size does not reduce parental feeding rate (Roulin et al. 2000). All experimental individuals fledged successfully. As also shown in another study (Dreiss et al. 2010a) keeping birds outside the nest is not stressful as measured by bloodcirculating corticosterone.

\section{RESULTS}

\section{Parental Feeding Behaviour}

At 1900 hours $1.1 \pm 2.6$ prey remains were present per nest and overnight parents brought $16.5 \pm 5.2$ voles. Thus, in the 21 nests we observed in total 346 parental feeding visits and an additional 56 cases where parents transferred to an offspring the remains of prey that were already lying on the nestbox floor before their arrival.

Per night, seniors and middle-born nestlings received twice as many prey items from parents as did their juniors (LMM: age rank: 
$F_{1,27}=7.04, P=0.013$; Table 1 ; nestling sex, absolute age and colour were not significant: all $P>0.63$ ). As a consequence, first- and middle-born owlets consumed more prey items per night than their junior nestmates (LMM: age rank: $F_{1,27}=4.30, P=0.04$; Table 1; nestling sex, absolute age and colour were not significant: all $P>0.10$ ). This indicates that first- and middle-born owlets had probably more opportunities to redistribute food to their subordinate siblings (see below).

\section{Nestling Food Consumption}

In total we observed 404 cases in which nestlings started to consume a prey item without finishing it; in 235 cases this item was recently given by a parent and in 169 cases this was surplus prey. We observed this behaviour more often in seniors than middleborn individuals and juniors (LMM: age rank: $F_{1,35}=4.26$, $P=0.047$; Table 1; nestling sex, absolute age and coloration were not significant: all $P>0.57$ ). This indicates that older nestlings have easier access to food and can perhaps consume the best parts of each prey item. Juniors took on average more time to eat an entire item than did seniors and middle-born nestlings (LMM: age rank: $F_{2,34.92}=3.49, P=0.04$; Table 1 ).

\section{Description of Food-sharing Events}

In $71 \%$ ( 15 of 21 ) of the three-chick broods, owlets fed nestmates from bill to bill on 46 occasions in total, representing one foodsharing event every $4 \mathrm{~h} 53 \mathrm{~min}$ or for every 7.5 prey items. On 23 occasions (50\%), food sharing was an active process with the donor clearly going towards a sibling to give it an item; in the 23 other cases the process was more passive with the donor and recipient being close to each other and it was not possible to determine whether the donor gave the prey item or simply did not react when the recipient took it. For subsequent analyses we pooled active and passive food-sharing events, as separate analyses gave qualitatively similar results. The donor transferred an item that it just obtained from a parent in 31 cases (67.4\%) and in the other 15 cases (32.6\%) it transferred prey remains.

\section{Food Sharing in Relation to Food Supply}

Food-sharing events occurred mainly when nestlings were hungry, that is at the beginning of the night rather than the end (Spearman correlation between the proportion of times prey items were shared and the order in which they were delivered by parents, i.e. first item of the night, the second item, and so on: $r_{\mathrm{S}}=-0.54$ $N=28, P=0.003$; Fig. 1a). However, the very first prey items of the night delivered by parents were usually not shared with siblings but rather quickly consumed (Fig. 1a). Indeed, at that time individuals were probably all hungry, as indicated by the fact that nestlings swallowed prey items instead of consuming them piece by piece more frequently at the beginning of the night than at the end (logistic regression for the probability that a prey item was

Table 1

Feeding behaviour in senior, middle-born and junior barn owl nestlings

\begin{tabular}{|c|c|c|c|}
\hline & Senior & Middle-born & Junior \\
\hline Prey items received from parents per night & $9.2 \pm 1.3$ & $7.7 \pm 0.8$ & $3.69 \pm 0.6$ \\
\hline Prey items entirely consumed per night & $3.9 \pm 0.4$ & $3.6 \pm 0.4$ & $2.9 \pm 0.4$ \\
\hline Prey items not entirely consumed per night & 7.7 & 6.7 & 4.8 \\
\hline $\begin{array}{l}\text { Mean time taken to consume an entire } \\
\text { prey item (s) }\end{array}$ & $36 \pm 6$ & $37 \pm 3$ & $59 \pm 9$ \\
\hline Prey items shared with siblings per night & 1.10 & 0.95 & 0.14 \\
\hline Prey items stolen from siblings per night & 0.57 & 0.42 & 0.62 \\
\hline
\end{tabular}

Behaviours were recorded from 1900 to 0700 hours in 21 three-chick broods. Means are quoted $\pm \mathrm{SE}$.
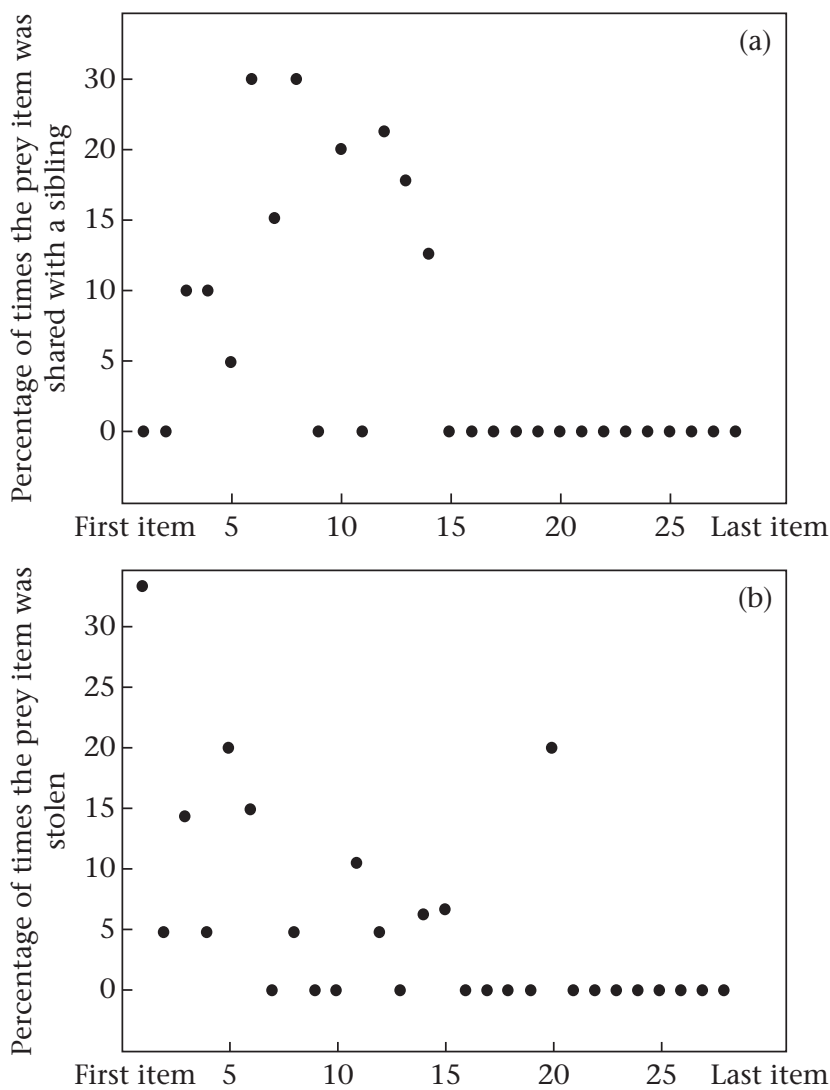

Order in which each food item was delivered by a parent

Figure 1. Probability that a food item was (a) shared with siblings or (b) stolen from a sibling in relation to the order in which this item was brought by a parent barn owl. The first item delivered during the night is represented by 1 on the $\mathrm{X}$ axis, the second delivered item by 2 , and so on. For example, across the 21 nests, the nestling that obtained the fifth prey item delivered by a parent did not eat it but offered it to one of its siblings in $5 \%$ of cases. In $20 \%$ of cases, a nestling stole or tried to steal this fifth item that its sibling had just obtained from its parent. Data are from 21 nests.

swallowed in relation to time: $\left.\chi^{2}=16.58, P<0.0001\right)$, probably because of the risk of being robbed (Roulin et al. 2008a).

If siblings share food to allow their parents to spend more time in foraging activities, we predicted parental feeding rate would be positively associated with the number of prey items shared between siblings. However, the total number of items transferred between nestmates in one night was not associated with the number of prey items available, that is, already present in the nests as prey remains at 1900 hours and delivered by parents during the night (GLM: number of prey remains: $F_{1,18}=0.02, P=0.90$; number of items brought by parents: $F_{1,18}=0.03, P=0.87$ ). Furthermore, the number of prey items that nestlings gave to their siblings was not associated with the number of items that the donors consumed throughout the night (GLMM: $F_{1,27}=1.98, P=0.17$ ). Therefore, variation in food sharing between and within broods was not determined by variation in food supply. Since nests with and without food sharing did not differ in mean nestlings' absolute age, body condition and mean phaeomelanin-based colour (logistic regression: all $P>0.11$ ), we considered only the nests in which food sharing occurred to examine whether siblings differentially expressed this helping behaviour.

\section{Food Sharing, Hatching Ranks and Coloration}

Seniors and middle-born nestlings fed their siblings more frequently than did juniors (Tables 1,2 ), as did darker compared to 
Table 2

Food sharing and food stealing in relation to the position in the within-brood age hierarchy of nestling barn owls

\begin{tabular}{llll}
\hline & \multicolumn{2}{l}{ Food recipient/Individual from which food was stolen } \\
\cline { 2 - 4 } & Senior & Middle-born & Junior \\
\hline Food donor & & 0.43 & 0.67 \\
Senior & - & - & 0.57 \\
Middle-born & 0.38 & 0.10 & - \\
Junior & 0.05 & & \\
Food stealer & & 0.33 & 0.24 \\
Senior & - & - & 0.14 \\
Middle-born & 0.29 & 0.29 & - \\
Junior & 0.33 & & \\
\hline
\end{tabular}

Behaviours were recorded from 1900 to 0700 hours in 21 three-chick broods. Food donors refer to individuals that gave a food item to a sibling; food recipients refer to individuals that were fed by a sibling. The oldest individual of three-chick broods is denoted 'senior', the youngest individual 'junior' and the intermediate individual 'middle-born'. Numbers indicate the mean number of items per night shared with a sibling or stolen from siblings.

light reddish phaeomelanic individuals (GLMM: age rank: $F_{2,25}=12.05, P=0.002$; colour: $F_{1,25}=9.21, P=0.006$; Fig. $2 \mathrm{a}-\mathrm{c}$; nestling sex, absolute age and the interaction between age rank and coloration were not significant: all $P>0.09$ ). In fact, juniors only very rarely fed their siblings (Table 1 ) suggesting that they do not reciprocate.

In the present study, dark and light melanic owls consumed a similar number of prey items per night (see above). The fact that darker birds shared food more often than lighter phaeomelanic siblings therefore suggests that dark phaeomelanic nestlings are more willing to feed siblings at the potential expense of eating less. If this is the case, we should expect that darker birds would consume fewer prey items before starting to feed nestmates. To examine this proposition, we considered only nestlings that fed at least one sibling and counted the prey items they consumed before sharing food. Among 19 individuals that fed siblings, they consumed between zero and four items $(1.6 \pm 0.2)$ before sharing food. Compared to light melanic nestlings, darker reddish individuals consumed fewer prey items before starting to feed nestmates (mixed model ANCOVA: colour: $F_{1,18}=4.43, P=0.04$; Fig. $2 \mathrm{~d}$; nestling sex: $F_{1,18}=11.15, P=0.004$; age rank was not significant: $P=0.60$ ). The factor sex was significant because nestling females started to feed nestmates earlier than nestling males.

\section{Food Stealing}

Nestlings stole $(N=16)$ or tried without success $(N=18)$ to steal a prey item from siblings on 34 occasions in 17 of the 21 nests (81\%). The total number of prey items shared between siblings and stolen from siblings was not correlated within nests (Spearman correlation: $r_{\mathrm{S}}=0.07, N=21, P=0.76$ ). Stealing events primarily concerned prey items that a nestling recently received from the bill of a parent (27 cases, $79.4 \%$ ); in seven cases (20.6\%) it concerned prey remains that a nestling was consuming. When considering only the prey items brought by parents, stealing events happened mainly at the beginning of the night (Spearman correlation between the proportion of times items had been stolen and the order in which they were delivered: $r_{\mathrm{S}}=-0.61, N=28, P=0.0005$; Fig. $\left.1 \mathrm{~b}\right)$. This is again consistent with the hypothesis that sibling competition is more intense at the beginning than at the end of the night.

The number of prey items stolen from siblings was related to the interaction between rank in the within-brood age hierarchy and coloration (GLMM: age rank: $F_{2,32}=3.86, P=0.03$; colour: $F_{1,32}=0.02, P=0.88$; interaction: $F_{2,32}=4.30, P=0.022$; the factor sex was not significant either alone or in interaction; Table 2 ). This interaction is explained by the fact that lighter-coloured seniors were more likely to steal a food item (Fig. 3a), whereas in juniors and middle-born nestlings the opposite significant relationship was found, with darker reddish birds being more likely to steal food (Fig. 3b, c).

\section{DISCUSSION}

Our correlative results suggest that by sharing food with siblings, nestling barn owls may derive indirect genetic benefits rather than direct material benefits. We are nevertheless aware that we cannot exclude the possibility that helping behaviour is also driven by pseudoreciprocity or by-product mutualism. Our observations also show how complex interactions between barn owl siblings can be. At the beginning of the night, competition over food items delivered by parents is high with most food-stealing events taking place at that time while very few food-sharing events occur. This leads nestlings to adopt specific begging behaviours to obtain food from parents (Dreiss et al. 2010b) and to avoid being robbed (Roulin et al. 2008a). This includes rapid food consumption by swallowing entire items more often at the beginning than at the end of the night. Once nestlings have consumed a few items, they start to be more generous by sharing food with siblings. This altruistic behaviour is observed mainly in the oldest dominant nestlings, particularly those displaying a female-specific plumage trait in the form of dark reddish phaeomelanin coloration. This suggests that female-like individuals of either sex behave more peacefully as further shown in female-like seniors that avoid stealing food from siblings. The opposite pattern is observed in middle-born nestlings and juniors displaying a female-specific coloration (i.e. dark reddish) since they are more likely to steal food.

The finding that barn owl nestlings frequently feed nestmates contradicts the view that, in vertebrates, competition over parental resources leads only to conflictual solutions, with siblicide as an extreme (Mock \& Parker 1997). It has been suggested that cooperation between siblings is used to attract the parents' attention (Johnstone 2004), although empirical evidence remains elusive (Smale et al. 1995; Roulin \& Dreiss 2012). Notwithstanding the evidence, although food sharing may not be widespread in young animals that compete over parental resources, it appears to be frequent in the barn owl. Although we observed food sharing in experimentally reduced broods, this behaviour has already been reported on several occasions in natural conditions (see Introduction). This shows that our observations are not artefacts of experimentally reducing brood size to three chicks, but is a general phenomenon in barn owl populations.

\section{Evolution of Food Sharing}

Our study raises the possibility that helping behaviour between young siblings does exist as predicted by kin selection theory (extrapair paternity is rare and hence nestmates are full-sibs; Roulin et al. 2004). A first reason why altruism between young siblings has rarely been observed in vertebrates is that altruistic behaviours may be difficult to detect. These instances may be rare (such as food sharing) requiring observations of behavioural interactions between siblings for many hours. Furthermore, if altruism involves begging behaviours as suggested by Johnstone (2004), it might not be easy to demonstrate that siblings adjust their begging level in a cooperative way (e.g. Blanc et al. 2010). Since food sharing may prevail in situations in which young offspring have access to stored food resources that can be used by offspring to feed their siblings, food sharing may be restricted to some particular groups of animals such as raptors (Baudvin 1980; Roulin 2004a). When nestlings are about 3 weeks of age, they 

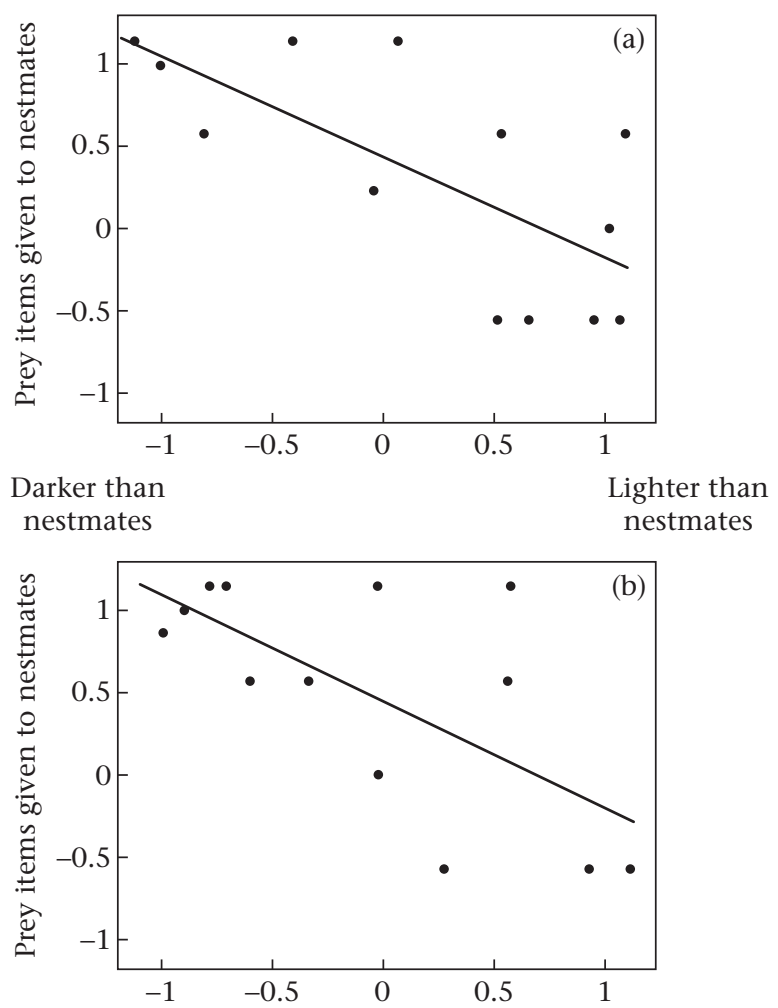

Darker than Lighter than nestmates nestmates

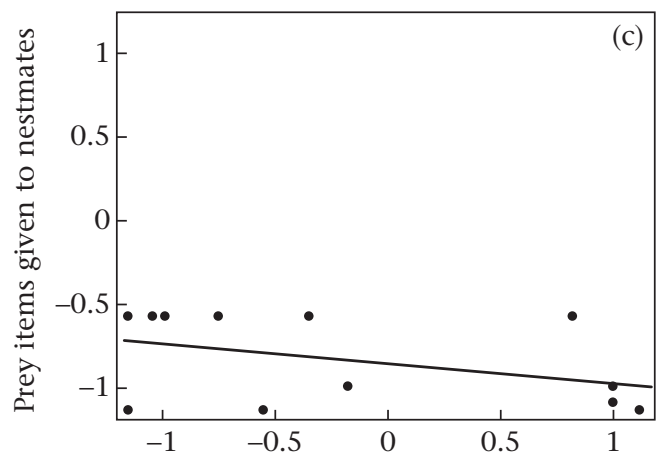

Darker than Lighter than nestmates nestmates

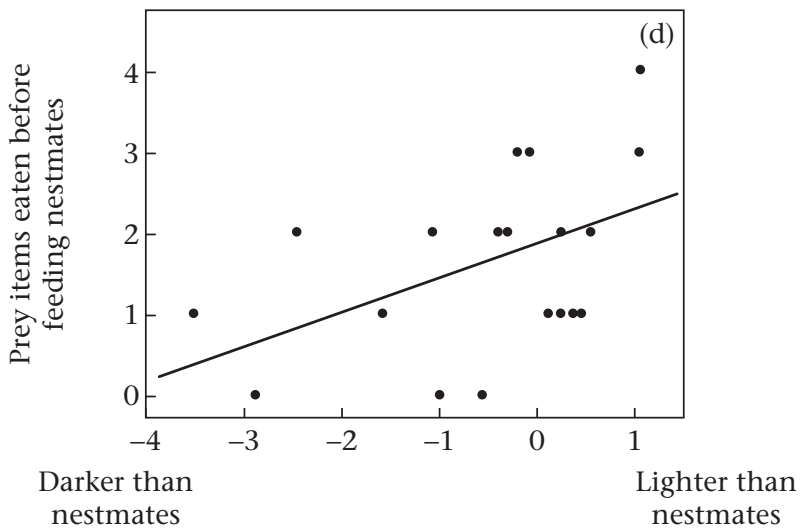

Phaeomelanin-based nestling coloration

Figure 2. $(a-c)$ Food sharing in relation to within-brood age hierarchy and phaeomelanin-based coloration in nestling barn owls. (a) Senior nestlings, (b) middleborn nestlings and (c) junior nestlings. (d) Number of prey items consumed by a nestling before it gave another item to a nestmate, in relation to nestling become able to consume food by swallowing entire items or by tearing apart flesh. Once a stored item is found, nestlings do not need assistance anymore, probably explaining why we did not observe nestlings feeding their siblings by tearing apart flesh but simply by transferring items from bill to bill. Our observations should stimulate researchers who have access to species with parents also delivering a surplus of food, as is the case in many owls and raptors, to investigate whether helping behaviour in the form of food sharing occurs in other species.

\section{Fitness Benefits of Sharing Food}

Two lines of arguments plead against the hypothesis that reciprocity helps maintain the occurrence of food sharing in the barn owl. First, senior and middle-born nestlings shared food with their siblings in contrast to juniors, which rarely feed their nestmates. This suggests that individuals may not feed siblings in expectation of a future return once they are hungry. Second, provisioning siblings may be a case of pseudoreciprocity or by-product mutualism. For instance, sharing food with siblings may be a form of sib-sib and parent-offspring altruistic behaviour (Kramer 2011). In large families, parents face a trade-off between the time spent looking for food and the time spent distributing it between their progeny. Barn owls can produce very large families with up to 10 young. Staggered births imply that when the first-born offspring begin to consume food without maternal help, their younger siblings still need assistance. The feeding of younger chicks by those older may therefore allow their parents to increase hunting activities. This possibility, however, is unlikely because feeding rate was not higher in broods in which we observed food sharing compared to broods without food sharing. Furthermore, the propensity to share food with siblings was not associated with offspring body condition. Another possibility is that nestlings feed their siblings to enhance their survival in order to increase the total level of begging solicitations that would induce parents to increase their feeding rate, allowing some nestlings (i.e. the dominant and darker reddish ones) to monopolize more food resources. This possibility, however, is unlikely because parents seem to allocate a fixed budget to feeding offspring and to be weakly sensitive to begging solicitations (Roulin et al. 2000). A last possibility is that nestlings help their siblings to reduce their own risk of being killed by a predator, a possibility that we cannot discuss further owing to the lack of data.

We therefore conclude that kin selection is likely to be a valid explanation to account for the evolutionary stability of food sharing among barn owl siblings. Accordingly, the costs paid by senior chicks to feed nestmates are probably low, whereas the derived inclusive fitness benefits may be considerable given that nestmates in barn owls are usually full siblings (Roulin et al. 2004).

\section{Food Sharing, Food Stealing and Coloration}

The propensity to feed siblings was associated with the degree of reddish phaeomelanin coloration, a strongly heritable trait

phaeomelanin-based coloration. We considered only 13 nests in which at least one prey item was exchanged between nestmates. The number of prey items given to nestmates was standardized, i.e. for each individual nestling we applied the following formula ([number of prey items this individual gave to siblings - mean number of items shared with siblings by the three siblings]/standard deviation of the number of items shared with siblings by the three siblings). We removed variation in phaeomelanin-based coloration explained by sex by extracting residuals from a oneway ANOVA $\left(F_{1,36}=5.64, P=0.023\right.$; although the two sexes can express any coloration, females are on average darker reddish than males). Then, for each nestling we standardized the residual values by applying the following formula ([residual colour score of the focal individual - mean residual coloration of the three siblings]/standard deviation of residual coloration of the three siblings). Pearson correlations: (a) $r_{11}=-0.70, P=0.007$; (b) $r_{11}=-0.66, P=0.014$; (c) $r_{10}=-0.40, P=0.20$. Regression lines are drawn for illustrative purposes. 

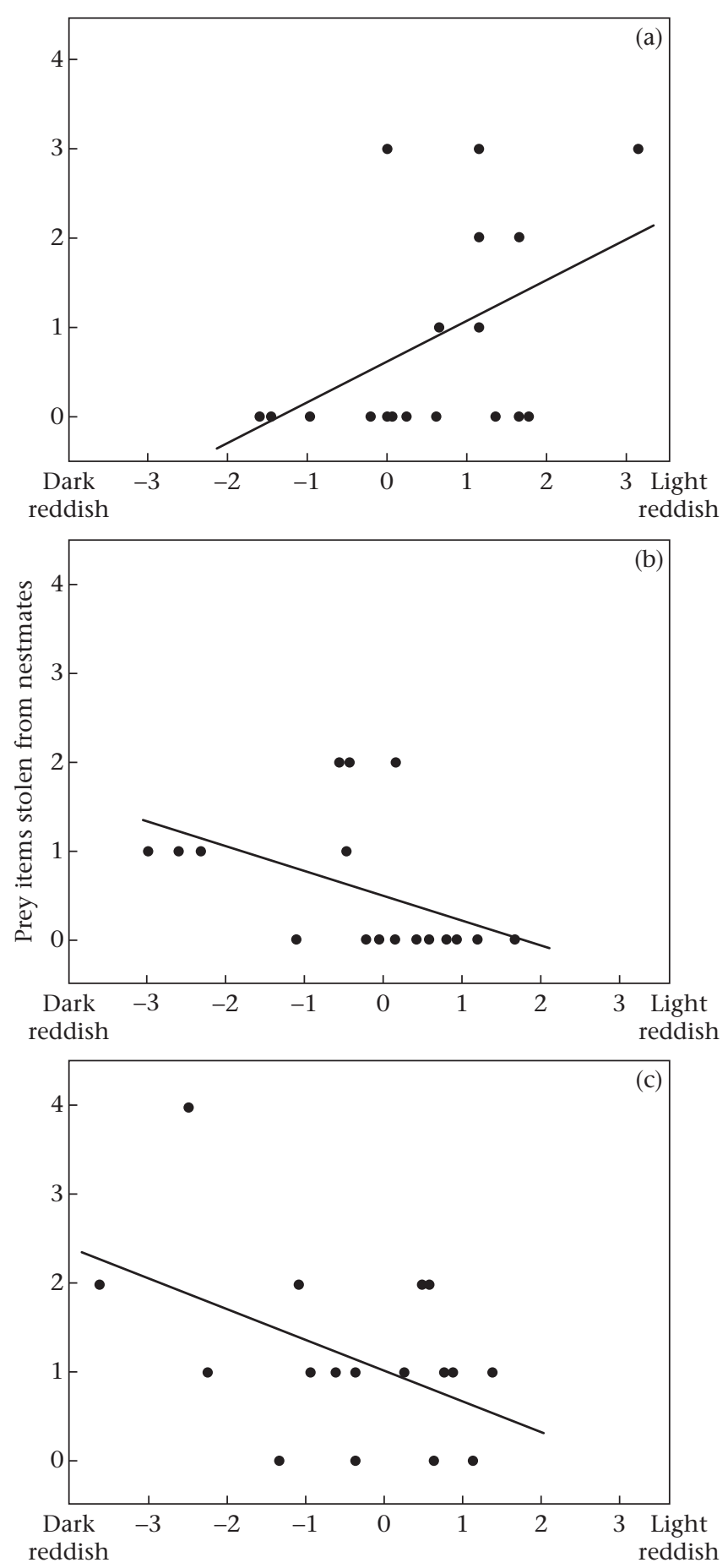

Residual phaeomelanin-based nestling coloration

Figure 3. Food stealing in relation to within-brood age hierarchy and phaeomelaninbased coloration in nestling barn owls. (a) Senior nestlings, (b) middle-born nestlings and (c) junior nestlings. Coloration was corrected for sex by extracting residuals from a one-way ANOVA with coloration as dependent variable and sex as a factor. Pearson correlations: (a) $r_{16}=0.49, P=0.032$; (b) $r_{16}=-0.46, P=0.048$; (c) $r_{16}=-0.48$, $P=0.046$. Regression lines are drawn for illustrative purposes.

$\left(h^{2} \pm \mathrm{SE}=0.81 \pm 0.09 ;\right.$ Roulin \& Dijkstra 2003). Because the expression of coloration is not or only weakly condition dependent (Roulin \& Dijkstra 2003), this indicates that food sharing may not only be determined by the resource-holding potential of each individual (i.e. seniority), but also be partly genetically controlled (Keller 2009). Explaining why darker reddish owls were more likely to share food with siblings and why in seniors darker individuals were also less likely to steal food from siblings is still a matter of speculation. We can propose two nonmutually exclusive mechanisms.

First, individuals displaying a female-like reddish coloration are more likely to share food, and in seniors (but not in middle-born and junior siblings) less likely to steal it. A female-like plumage is therefore associated with helping behaviour in dominant individuals, whereas a male-like plumage (i.e. light reddish to white) is linked with agonistic behaviour. Because in animals males are commonly more aggressive than females (Lindenfors \& Tullberg 2011; Senar \& Domenech 2011), we propose that a dark reddish coloration could be related to female-specific behaviour. This is consistent with the observation that the motivation to feed siblings (measured in number of prey items consumed before sharing food with siblings) was not only related to phaeomelanin-based coloration but also higher in females than males. This raises the exciting possibility not only that females are more altruistic than males but also that feminine plumage traits are associated with the propensity to be generous. Second, our results could be explained by the fact that when food is available in large quantities, darker phaeomelanic individuals increase their body mass more rapidly than lighter-coloured ones (Roulin et al. 2008b). Under this scenario, dark reddish individuals need less food and hence can share it with their siblings to derive at least indirect genetic benefits.

\section{Conclusion}

Two pieces of evidence suggest that sharing food with siblings entails some fitness costs. First, food sharing occurs mainly at the beginning of the night (when nestlings are hungry) but only after food donors consumed a couple of prey items. Second, sharing food prevails in dominant individuals but not in subordinate nestlings probably because dominant nestlings have privileged access to food resources that they can redistribute among siblings. Given the potential costs of food sharing, this helping behaviour should confer some fitness advantages if it is to persist. As discussed above, nestlings may derive indirect benefits through kin selection (and eventually direct benefits through pseudoreciprocity or by-product mutualism). Our study therefore adds a new element to the potential role played by kin selection in the evolution of altruism, namely among young vertebrates that are still dependent on their parents. This system in which related individuals are confined in a limited space, and hence can develop iterative altruistic interactions, mirrors the case of cooperative breeding among mature related individuals (West et al. 2007; Cornwallis et al. 2009).

\section{Acknowledgments}

We thank Philippe Christe, Raphaelle Flint, Philipp Heeb, Mathias Kölliker, Alexandre Chausson and two anonymous referees for useful comments and the Swiss National Science Foundation for funding to A.R. (31003A-120517).

\section{References}

Bakaloudis, D. E., Lezekiel, S., Vlachos, C. G., Bontzorlos, V. A., Papakosta, M. \& Birrer, S. 2012. Assessing bias in diet methods for the long-legged buzzard Buteo rufinus. Journal of Arid Environments, 77, 59-65.

Baudvin, H. 1980. Les surplus de proies au site de nid chez la chouette effraie, Tyto alba. Nos Oiseaux, 35, 232-238.

von Bayern, A. M. P., de Kort, S. R., Clayton, N. S. \& Emery, N. J. 2007. The role of food- and object-sharing in the development of social bonds in juvenile jackdaws (Corvus monedula). Behaviour, 144, 711-733.

Bergmüller, R., Johnstone, R. A., Russell, A. F. \& Bshary, R. 2007. Integrating cooperative breeding into theoretical concepts of cooperation. Behavioural Process, 76, 61-72. 
Blanc, A., Ogier, N., Roux, A., Denizeau, S. \& Mathevon, N. 2010. Begging coordination between siblings in black-headed gulls. Comptes Rendus Biologies, 333 688-693.

Bshary, R. \& Bergmuiller, R. 2007. Distinguishing four fundamental approaches to the evolution of helping. Journal of Evolutionary Biology, 21, 405-420.

Bühler, P. 1981. Das Fütterungsverhalten der Schleiereule Tyto alba. Okologie der Vögel, 3, 183-202.

Clutton-Brock, T. 2002. Breeding together: kin selection and mutualism in cooperative vertebrates. Science, 296, 69-72.

Cornwallis, C. K., West, S. A. \& Griffin, A. S. 2009. Routes to indirect fitness in cooperatively breeding vertebrates: kin discrimination and limited dispersal. Journal of Evolutionary Biology, 22, 2445-2457.

Dreiss, A., Henry, I., Ruppli, C., Almasi, B. \& Roulin, A. 2010a. Darker eumelanic barn owls better withstand food depletion through resistance to food deprivation and lower appetite. Oecologia, 164, 65-71.

Dreiss, A., Lahlah, N. \& Roulin, A. 2010b. How siblings adjust sib-sib communication and begging signals to each other. Animal Behaviour, 80, 1049-1055.

Drummond, H., Rodriguez, C., Vallarino, A., Valderrabano, C., Rogel, G. \& Tobon, E. 2003. Desperado siblings: uncontrollably aggressive junior chicks Behavioral Ecology and Sociobiology, 53, 287-296.

Epple, W. 1979. Geschwisterfütterung bei jungen Schleiereulen Tyto alba. Journal für Ornithologie, 120, 226.

Hamilton, W. D. 1964. The genetical evolution of social behaviour. I. Journal of Theoretical Biology, 7, 17-52.

Hatchwell, B. J. 2010. Cryptic kin selection: kin structure in vertebrate populations and opportunities for kin-directed cooperation. Ethology, 116, 203-216.

Johnstone, R. A. 2004. Begging and sibling competition: how should offspring respond to their rivals? American Naturalist, 163, 388-406.

Keller, L. 2009. Adaptation and the genetics of social behaviour. Philosophical Transactions of the Royal Society B, 364, 3209-3216.

Kilner, R. M., Madden, J. R. \& Hauber, M. E. 2004. Brood parasitic cowbirds use host young to procure food. Science, 305, 877-879.

Kniprath, E. \& Stier-Kniprath, S. 2010. Schleiereule Tyto alba: Jungvogel an Geschwister verfüttert. Eulen-Rundblick, 60, 66-68.

Kokko, A., Johnstone, R. A. \& Clutton-Brock, T. H. 2001. The evolution of cooperative breeding through group augmentation. Proceedings of the Royal Society B, 268, 187-196.

Korpimäki, E. 1987. Prey caching of breeding Tengmalm's owls Aegolius funereus as buffer against temporary food shortage. Ibis, 129, 499-510.

Kramer, K. L. 2011. The evolution of human parental care and recruitment of juvenile help. Trends in Ecology \& Evolution, 26, 533-540.

Lehmann, L. \& Keller, L. 2006. The evolution of cooperation and altruism: a genera framework and a classification of models. Journal of Evolutionary Biology, 19, $1365-1376$.

Leimar, 0. \& Hammerstein, P. 2010. Cooperation for direct fitness benefits. Philosophical Transactions of the Royal Society B, 365, 2619-2626.

Lindenfors, P. \& Tullberg, B. S. 2011. Evolutionary aspects of aggression: the importance of sexual selection. Advances in Genetics, 75, 7-22.

Marti, C. D. 1989. Food sharing by sibling common barn owls. Wilson Bulletin, 101, $132-134$
Mock, D. W. \& Parker, G. A. 1997. The Evolution of Sibling Rivalry. Oxford: Oxford University Press.

Py, I., Ducrest, A.-L., Duvoisin, N., Fumagalli, L. \& Roulin, A. 2006. Ultraviolet reflectance in a melanin-based plumage trait is heritable. Evolutionary Ecology Research, 8, 483-489.

Roulin, A. 1999. Nonrandom pairing by male barn owls (Tyto alba) with respect to female plumage trait. Behavioral Ecology, 10, 688-695.

Roulin, A. 2001. Food supply differentially affects sibling negotiation and competition in the barn owl (Tyto alba). Behavioral Ecology and Sociobiology, 49, 514519.

Roulin, A. 2004a. The function of food stores in bird nests: observations and experiments in the barn owl Tyto alba. Ardea, 92, 69-78.

Roulin, A. 2004b. Effects of hatching asynchrony on sibling negotiation, begging jostling for position and within-brood food allocation in the barn owl Tyto alba. Evolutionary Ecology Research, 6, 1083-1098.

Roulin, A. \& Bersier, L.-F. 2007. Nestling barn owls beg more intensely in the presence of their mother than in the presence of their father. Animal Behaviour 74, 1099-1106.

Roulin, A. \& Dijkstra, C. 2003. Genetic and environmental components of variation in eumelanin and phaeomelanin sex-traits. Heredity, 90, 359-364.

Roulin, A. \& Dreiss, A. N. 2012. Sibling competition and cooperation over parenta care. In: The Evolution of Parental Care (Ed. by N. Royle, M. Kölliker \& P. Smiseth) pp. 133-149. Oxford: Oxford University Press.

Roulin, A., Kölliker, M. \& Richner, H. 2000. Barn owl (Tyto alba) siblings vocally negotiate resources. Proceedings of the Royal Society B, 267, 459-463.

Roulin, A., Müller, W., Sasvari, L., Dijkstra, C., Ducrest, A.-L., Riols, C., Wink, M. \& Lubjuhn, T. 2004. Extra-pair paternity, testes size and testosterone level in relation to colour polymorphism in the barn owl Tyto alba. Journal of Avian Biology, 35, 492-500.

Roulin, A., Colliard, C., Russier, F., Fleury, M. \& Grandjean, V. 2008a. Sib-sib communication and the risk of food theft in the barn owl. Journal of Avian Biology, 39, 593-598.

Roulin, A., Gasparini, J., Bize, P., Ritschard, M. \& Richner, H. 2008b. Melanin based colorations signal strategies to cope with poor and rich environments. Behavioral Ecology and Sociobiology, 62, 507-519.

Senar, J. C. \& Domenech, J. 2011. Sex-specific aggression and sex ratio in wintering finch flocks: serins and siskins differ. Acta Ethologica, 14, 7-11.

Smale, L., Holekamp, K. E., Weldele, M., Frank, L. G. \& Glickman, S. E. 1995 Competition and cooperation between litter-mates in the spotted hyaena, Crocuta crocuta. Animal Behaviour, 50, 671-682.

Trivers, R. L. 1971. The evolution of reciprocal altruism. Quarterly Review of Biology, 46, 35-57.

Trivers, R. L. 1974. Parent-offspring conflict. American Zoology, 14, 249-264.

West, S. A., Pen, I. \& Griffin, A. S. 2002. Conflict and cooperation - cooperation and competition between relatives. Science, 296, 72-75.

West, S. A., Griffin, A. S. \& Gardner, A. 2007. Social semantics: altruism, cooperation, mutualism, strong reciprocity and group selection. Journal of Evolutionary Biology, 20, 415-432.

Wilkinson, G. S. 1992. Communal nursing in the evening bat, Nycticeius humeralis Behavioral Ecology and Sociobiology, 31, 225-235. 